\title{
The prevalence and costs of obesity in the $\mathrm{EU}$
}

\author{
James Fry $^{1 *}$ and Willa Finley ${ }^{2}$ \\ ${ }^{1}$ LMC International, 14-16 George Street, Oxford OX1 2AF, UK \\ ${ }^{2}$ LMC International, 1841 Broadway, New York, NY 10023, USA
}

\begin{abstract}
The present paper reports on results obtained as part of the economics module of the LIPGENE project. It reviews recent trends in obesity in the fifteen member states of the EU (the member states before enlargement in 2004) and concludes that in 2002 for both adult men and women at least half the fifteen member states of the EU had obesity levels of $>20 \%$. In the same year the total direct and indirect annual costs of obesity in the fifteen member states of the EU were $€ 32800 \times 10^{6}$. The provision of 'healthy' foods with an adapted lipid profile provides one means of mitigating the impact of obesity. However, there are extra costs associated with the supply of such foods, via additional costs of food ingredients, identity preservation costs for premium-value food products and the penalties caused by the inability to exploit economies of scale. The limited scale of the markets for healthy foods is caused by their high selling prices. Also presented is an analysis of the costs of subsidising, throughout the EU, ingredients that improve the fatty acid profile of beef, eggs, poultry meat and low-fat spreads, so that healthier versions of these products sell at the same price as traditional alternatives. The total costs of such subsidies for these four food products would have been $€ 10 \times 10^{9} /$ year in 2002 , which was $30 \%$ of the direct and indirect costs of obesity.
\end{abstract}

\section{Obesity: Identity preservation: Healthy foods}

The present paper reports on some of the initial results obtained as part of work package 4 , the economics module, of the LIPGENE project (see Buttriss \& Nugent, 2005). It reviews recent trends in the incidence of adult obesity in the fifteen member states of the EU (the member states before enlargement in 2004) and estimates the direct and indirect health-related costs of these levels of obesity. It then examines the costs of preparing special segregated identity-preserved supply chains from the farm to the retailer for supplying food products with an adapted lipid profile intended to reduce the number of individuals suffering from the metabolic syndrome and its associated costs. It reviews the trade-off between the premium prices charged for some healthy foodstuffs and the market shares that they capture. Finally, it considers the costs of potential policy initiatives, such as subsidies to reduce the retail prices of healthy foods and increase their sales, in relation to the current costs of obesity.

\section{The incidence of obesity}

It is difficult to obtain internationally-consistent data on the incidence of obesity (defined as a BMI of $>30 \mathrm{~kg} / \mathrm{m}^{2}$ ).
The Organization for Economic Cooperation and Development (2004) publishes data that provide patchy annual coverage for many of the fifteen member states of the EU (pre2004 member states), and no coverage for Luxembourg. Furthermore, many of the Organization for Economic Cooperation and Development series of data rely on the self-reporting of both weight and height by individuals, which understates the true incidence, and some data are also drawn from only particular groups within the adult population. Fig. 1 indicates national adult obesity levels in 2002 if each country's historical time trends are extended to 2002. For both men and women at least half the member states had obesity levels of $>20 \%$ in 2002 .

\section{The direct and indirect health costs of obesity}

The UK National Audit Office (Comptroller and Auditor General, 2001) has published a report, based on 1998 data, that provides estimates of the direct costs (of obesityrelated primary medical consultation, hospital treatment and medicines) and indirect costs (derived from the number of days taken off for sickness as a result of

\footnotetext{
*Corresponding author: Dr James Fry, fax +44 1865791 739, email jfry@Lmc.co.uk
} 
(a)

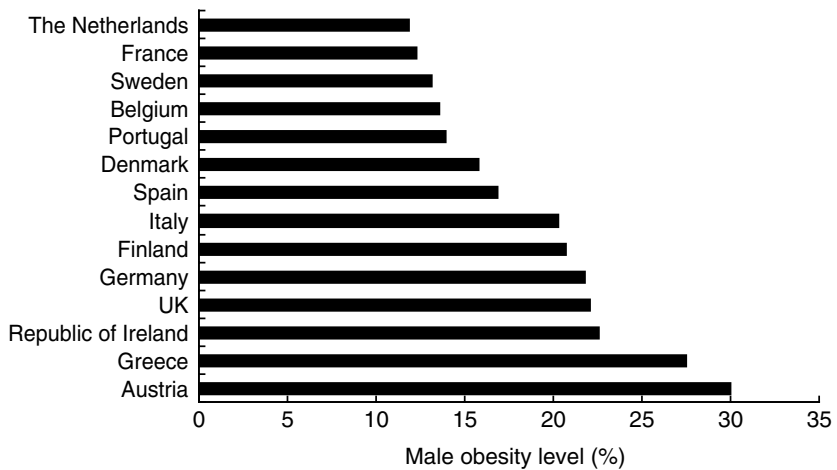

(b)

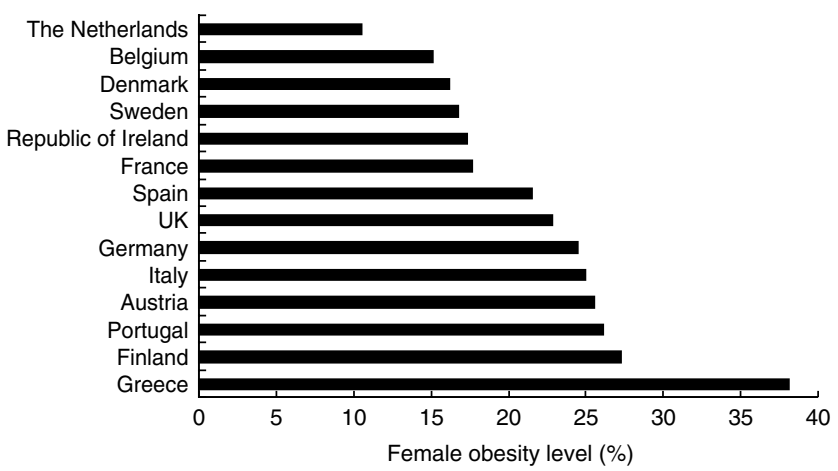

Fig. 1. Trend estimates in 2002 for the percentage of adult males (a) and females (b) with a BMI of $>30 \mathrm{~kg} / \mathrm{m}^{2}$ for the fifteen member states of the EU.

obesity-related illnesses and from early deaths as a consequence of the same illnesses) of obesity in England. The estimated costs for the fifteen member states of the EU in 2002 are shown in Fig. 2, which has been compiled from the 1998 National Audit Office study (Comptroller and Auditor General, 2001) by applying the following assumptions: (a) the 2002 trend levels of obesity are applied for each member state; (b) a country with the same level of total health expenditures in 2002 that England had in 1998 but an average adult obesity level in 2002 that is, for example, one-fifth higher than that in England in 1998 is assumed to face direct and indirect costs of obesity that are one-fifth higher than those estimated for England in 1998; (c) a country with, for example, half the overall health expenditures in 2002 that England recorded in 1998 but the same level of obesity in 2002 that England recorded in 1998 is assumed to face direct and indirect costs of obesity that are half those estimated for England in 1998. The total direct and indirect cost of obesity for the fifteen member states of the EU in 2002 was estimated to be approximately $€ 32800 \times 10^{6} \%$ year. (It is reassuring to find that the cost estimate for Ireland (Republic of Ireland and Northern Ireland), based on this methodology, is similar to that derived in 2003 by an independent study in Ireland (D O'Shea, T O'Sullivan, JM Reilly, M Ryan, S McCarthy, Y Ryan, S Sreenan, V Maher, C Costigan and M Laffoy, unpublished results), working from the National Audit Office methodology (Comptroller and Auditor

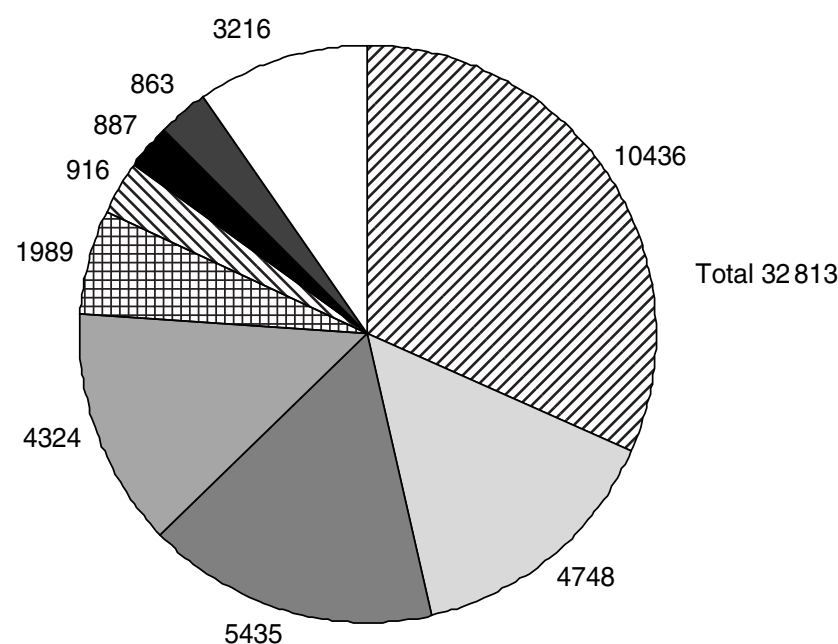

Fig. 2. Total direct and indirect costs $\left(€ \times 10^{6}\right)$ of obesity (where these costs are attributed pro rata by country to UK data for 1998 derived from Comptroller and Auditor General (2001)) in 2002 for the fifteen member states of the EU. (Z), Germany; ( $\square$ ), Italy; $(\square)$, UK; $(\square)$, France; $(\mathbb{\boxplus})$, Spain; $(\mathbb{\mathbb { \nabla }})$, Austria; $(\square)$, The Netherlands; ( $\square)$, Greece; ( $\square$ ), others.

General, 2001). It should be noted that the National Audit Office study (Comptroller and Auditor General, 2001) and other studies, including several addressing obesity in the USA (Wolf \& Colditz, 1998; American Obesity Association, 2002; National Center for Health Statistics and US Centers for Disease Control and Prevention, 2002; Finkelstein et al. 2003), acknowledge that the National Audit Office methodology yields conservative estimates of costs and is at the lower end of the spectrum in relation to estimates of the full economic impact of the metabolic syndrome.

\section{The costs of providing identity-preserved foodstuffs}

The costs of providing special foods with healthy attributes are higher than those for the supply of conventional foodstuffs for three main reasons. One reason is the higher cost of the ingredients needed to produce a healthy food; for example, the extra costs of feeding fish oil to dairy cows. Another reason is the additional costs imposed on farmers, producers, distributors and retailers by a lack of scale in their operations. The third reason is that identity preservation costs are incurred to prevent valuable food products becoming intermingled with less-valuable products and thus losing their special value.

Fig. 3 uses US data to illustrate the cost penalties imposed on suppliers of milk with a high conjugated linoleic acid content, achieved by feeding cows with fish oil (Maynard \& Franklin, 2003). On the farm the costs of providing the ingredients necessary for a high conjugated linoleic acid content are higher than the costs of identity preservation. This disparity is partly because a typical farm is sufficiently self-contained with a dedicated operation to be able to hold to a minimum the costs of identitypreserved systems. For processors and retailers economies of scale are much more important in explaining differences 


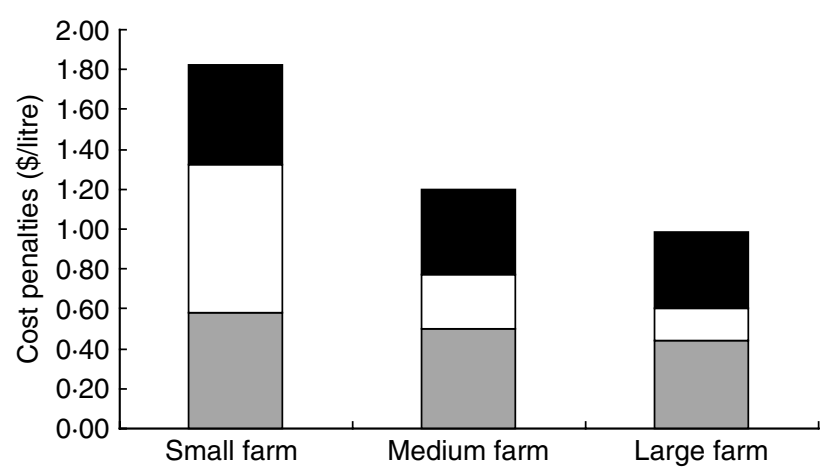

Fig. 3. US economies of scale along the farm ( $\square$ )-processing $(\square)$-retail ( $\square$ ) chain for high-conjugated linoleic acid fresh milk production for small, medium and large farms.

in delivered costs than identity-preserved costs or higher ingredient costs.

\section{Trade-off between prices and market shares for novel healthy foods}

Fig. 4 illustrates a UK example of the trade-off between premium prices for novel products with healthy attributes and the market shares that they capture. The small number of data points describe the relatively small market shares and high price premiums that are currently associated with novel healthy foodstuffs with a potential market share (of $100 \%$ ) that the healthier product might command if it were sold at no premium at all, or at a very small discount to the traditional conventional alternative.

Large price reductions from present levels would be needed to boost the sales of the novel healthier food products substantially. Without such reductions most consumers would not be willing to pay the prices needed to cover the costs of developing and maintaining a separate supply chain for small volumes of sales.

\section{The possibility of subsidising the supply of healthy foods}

Data relating to the costs of supplying healthy forms of eggs, poultry meat, beef and low-fat spreads (Darling, 2001; Fanatico \& Redhage, 2002; Food Standards Agency, 2004; J Marquardt, personal communication) have been used to estimate the total costs of subsidising the special ingredients for these healthy food products in order to bring their production costs down to those of conventional (less-healthy) products in the fifteen member states of the EU (pre2004 member states). The size of this subsidy has been estimated by applying the proportion of extra costs (for special input ingredients, such as phytosterols in spreads or fish oil and flax seed in feed, and also the opportunity costs of yield reductions that result from feeding these ingredients) for each of these four products across their respective EU retail market segments in 2002. It has been assumed that by eliminating any cost disadvantage for the healthier products these products

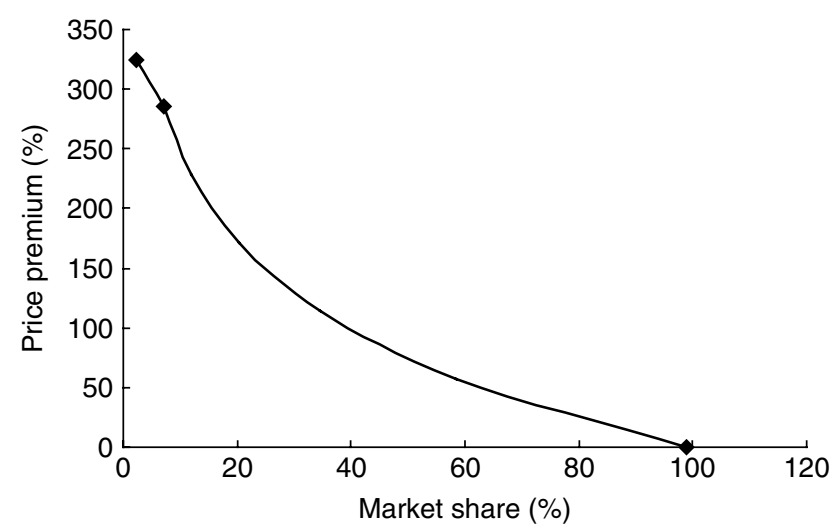

Fig. 4. Price premiums and market share in the UK for highphytosterol low-fat spreads, using data points describing the relatively small market shares and high price premiums that are currently associated with novel healthy foodstuffs with a potential market share (of $100 \%$ ) that the healthier product might command if it were sold at no premium at all or at a very small discount to the traditional conventional alternative.

will replace the current mainstream foodstuffs from the market (this logic is the same as that on which Fig. 4 is based).

The extra costs of subsidising the supply of healthy ingredients for these products are then contrasted with the annual direct and indirect costs of obesity, shown in Fig. 2. It should be emphasised that this approach is not meant to imply that this outlay on subsidies would yield the elimination of obesity; rather, it is intended to illustrate the relative orders of magnitude of the costs of comprehensive official intervention in the supply of major foodstuffs, on the one hand, and the current costs caused by obesity, on the other.

Fig. 5 compares the monetary costs of such subsidies with the overall direct and indirect costs of obesity in the fifteen member states of the EU in 2002; the former (at approximately $€ 10 \times 10^{9}$ ) amounts to $30 \%$ of the costs of obesity (of approximately $€ 33 \times 10^{9}$ ).

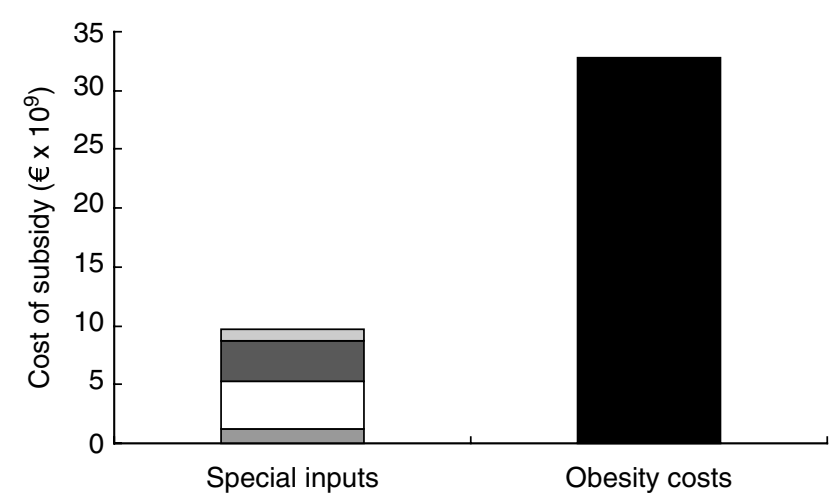

Fig. 5. Costs of subsidising inputs on novel egg ( $\square$ ), broiler ( $\square$ ), beef $(\square)$ and low-fat spread $(\square)$ output $v$. the direct and indirect costs of obesity ( $\boldsymbol{\square})$ in 2002 in the fifteen member states of the EU. 


\section{Conclusions}

The incidence of adult obesity has risen steadily in almost every EU member state, for both men and women. In 2002 approximately half the member states already had $20 \%$ of men and women with BMI of $>30 \mathrm{~kg} / \mathrm{m}^{2}$. In 2001 the UK National Audit Office (Comptroller and Auditor General, 2001) published a detailed study of the economic costs of obesity. The application of its methodology to all fifteen member states of the EU has provided estimates for the combined direct and indirect costs of obesity in 2002 of approximately $€ 33 \times 10^{9} /$ year.

The provision of fat-modified 'healthy' foods provides one possible means of mitigating the health consequences and costs of obesity. However, there are extra costs associated with the supply of such foods. These extra costs arise in the form of the additional costs for feed additives and food ingredients, the opportunity costs of the reduced yields of animals supplied with these special feed additives, the identity preservation costs of maintaining separate supply chains for premium-value food products and the penalties caused by the inability to exploit economies of scale in farming, processing and distribution.

The limited scale of the current markets for these healthy foods is largely a function of their high selling prices. The present paper provides a simple analysis of the costs of subsidising across-the-board, for the entire EU market, special feed ingredients and food additives that improve the fatty acid profile of a number of important foods (beef, eggs, poultry meat and low-fat spreads) so that the full costs, inclusive of production, processing and distribution costs, of the healthier versions of these products are no higher than those for the traditional alternatives.

The analysis reveals that the total costs of such subsidies for these four food products would have amounted to $€ 10 \times 10^{9} /$ year in 2002 , if no attempt had been made to target the use of these products to particular segments of the population, such as obese individuals. Thus, this sum should be considered to represent an upper limit to the likely costs of providing healthier forms of these foods to help to reduce the health-related costs (of a minimum of $€ 33 \times 10^{9} /$ year) caused by obesity.

\section{References}

American Obesity Association (2002) Costs of obesity. http:// www.obesity.org/treatment/cost.shtml

Buttriss J \& Nugent A (2005) LIPGENE: an integrated approach to tackling the metabolic syndrome. Proceedings of the Nutrition Society 64, 345-347.

Comptroller and Auditor General (2001) Tackling Obesity in England. Appendix 6: Estimating the Cost of Obesity in England. London: Stationery Office.

Darling T (2001) Commercial Beef Niche Market Alternatives. Agriculture Business Profiles. Edmonton, Alberta: Alberta Agriculture, Food and Rural Development.

Fanatico A \& Redhage D (2002) Growing Your Range Poultry Business. Fayetteville, AR: National Center for Appropriate Technology.

Finkelstein EA, Fiebelkorn IC \& Wang G (2003) National medical spending attributable to overweight and obesity: how much, and who's paying? Health Affairs W3:219-226. http://content.healthaffairs.org/cgi/content/full/hlthaff.w3. 219v1/DC1

Food Standards Agency (2004) Notification Dossier: Phytosterols and their esters for use as an ingredient in a range of food applications. Cognis Deutschland GmbH. http://www.food.gov.uk/multimedia/pdfs/Cognis.pdf

Maynard LJ \& Franklin ST (2003) Functional foods as a valueadded strategy: The commercial potential of 'cancer-fighting' dairy products. Review of Agricultural Economics 25, 316-331.

National Center for Health Statistics and US Centers for Disease Control and Prevention (2002) Prevalence of overweight and obesity among adults: United States, 1999-2002. http:// www.cdc.gov/nchs/products/pubs/pubd/hestats/obese/ obse99.htm

Organization for Economic Cooperation and Development (2004) OECD health data 2004. Overweight or obese population (updated 8 February 2004). www.irdes.fr/ecosante/OCDE/ 814010.html

Wolf AM \& Colditz GA (1998) Current estimates of the economic cost of obesity in the United States. Obesity Research 6, 97-106. 